\title{
Effectiveness of Ozone Treatment for Chronic Anal Fistula
}

\author{
Tahoor Ahmed Khan ${ }^{1}$, Rida Fatima ${ }^{2}$, Haseeb Akbar $^{3}$ \\ 1,2,3. House Officer Bahawal Victoria Hospital Bahawalpur
}

\begin{abstract}
:
Objective: To find out if the ozone treatment is promising for chronic anal fistula. Study Design: Non Randomized Trial.Study Location and Duration: General Surgery Department Bahawal Victoria Hospital Bahawalpur. From 20 December 2017 to 28 February 2019. Material and methods: A total of 57 patients were included in our study. Success of the treatment was based upon the cessation of the discharge and closure of the anorectal fistula at the end of the treatment. Statistical analysis was done using computer software SPSS version 23. Mean and standard deviation was calculated for continuous variables like age etc. and frequency and percentage was taken for categorical variables like, gender etc. Comparison of number of sessions for healing and non healing patients was done using a $t$ test. $\mathrm{P}$ value of less than or equal to 0.05 was taken as significant. Results: A total of 57 patients presenting with anorectal fistula were included in the study. A total of 19 patients received 60 volume of ozone, 23 received 120 volume of ozone and remaining 15 received 180 volume of ozone. Means and standard deviation of sessions of treatment with ozone was 8.29 \pm 3.66 . Closure of the fistula was seen in only 14 patients while 43 did not show any improvements or they had reoccurrence of anorectal fistula after getting treatment with ozone. Conclusion: On the basis of the results of this study, it can be concluded that ozone insufflation is not a promising treatment option for the treatment of anorectal fistula. There were no associated side effects of ozone insufflation. Further studies are required with larger sample size.
\end{abstract}

Keywords: Ozone Insufflation, Anal Fistula, Enterocutaneous Fistula

DOI: $10.7176 / \mathrm{JMPB} / 55-20$

Publication date:May $31^{\text {st }} 2019$

\section{Introduction:}

After the surgical drainage or spontaneous drainage of anorectal abscess, an enterocutaneous fistula develops known as anorectal fistula ${ }^{1}$. Anorectal fistula poses serious and disturbing effects in perianal region in terms of moisture, discharge and recurrent abscess ${ }^{2}$. Its spontaneous recovery is near to impossible. The usual and standard treatment for this condition is surgery ${ }^{3}$. Through surgery, elimination and prevention of recurrence of fistula is obtained along with maintenance of anal continence. Patients face serious problems if fistula reoccurs or if anal continence is compromised postoperatively. Therefore research is still going on to find out various possible treatments of anorectal fistula. Ozone gas is composed of three oxygen atoms and it occurs naturally ${ }^{4}$. Ozone is usually used as a powerful disinfectant, as it can inactivate a large number of pathogens ${ }^{5}$. It has also been shown to enhance the recovery by stimulating cell proliferation ${ }^{6}$. Ozone which is usually used in medical field is known as medical ozone and comprises of five percent ozone and 95 percent oxygen ${ }^{7}$. In blood, it is dissolved as an antioxidant and affects multiple organs by producing lipid oxidation products and oxygen radicals ${ }^{8}$. Its mechanism of action has been thoroughly understood and explained in the previous literature. Ozone has been used in the treatment of multiple diseases including, degenerative lumbar diseases and infections. Mode of administration of ozone into the human body is variable and there are different ways to supply ozone to the body like, intramuscular route, subcutaneous route, intravenous, intraperitoneal, intraarticularly, intrapleurally, nasally, rectally and intralesionally. Owing to the healing effect of ozone, it has been used in some chronic inflammatory diseases similar to anorectal fistula ${ }^{9}$. But it has never been used in the treatment of anorectal fistula before except in one study. The rationale of this study is to assess the healing effect of ozone in treatment of anorectal fistula in adult patients after ozone gas insufflation to the anorectal fistula.

\section{Material and Method:}

This is a prospective study performed in General Surgery Department Bahawal Victoria Hospital Bahawalpur. From 20 December 2017 to 28 February 2019.. Ethical approval for this study was obtained from the hospital ethics committee. A total of 57 patients were included in our study. Non probability consecutive sampling technique was used to collect the sample size. Sample size was calculated using the reference study ${ }^{10}$. Inclusion criteria were as follows, patients without infection and one fistula orifice and those who preferred ozone insufflation treatment were included in the study. While patients with infections, discharge from the fistula, more than one fistula orifices and concomitant anal disease were excluded from the study. All the patients gave informed written consent and procedure was thoroughly explained and advantages and disadvantages of surgery 
and ozone insufflation were also explained before the inclusion into the study. All the patients completed the treatment and analysis of the results of the treatment was done at the end of the study.

Ozone insufflation was performed in prone position. No type of anesthesia, analgesia or sedative was applied before or during the insufflation process. After identifying the outer opening of the anorectal fistula a 20 gauge IV cannula was inserted at 2 to $3 \mathrm{~mm}$ from the fistula orifice. Medical ozone was pulled into the injector from an ozone production device and then injector was introduced into the anorectal fistula. Concentration of ozone gas was adjusted according the amount of discharge from the fistula within the range of 10 to $40 \mu \mathrm{g} \backslash \mathrm{ml}$. greater the amount of discharge higher the concentration of ozone insufflated. Volume of ozone gas being insufflated was in between the range of 60 to $180 \mathrm{ml}$, depending upon the sensation of insufflation of the gas in to the fistula as described by the patients. After insufflation, cannula was removed and there was no need of dressing to the perianal region. A total of 10 sessions were planned for each patient on alternate days. Further sessions were performed if there was evidence of significant decrease on the amount of discharge from the anorectal fistula.

Success of the treatment was based upon the cessation of the discharge and closure of the anorectal fistula at the end of the treatment. On the other hand if discharge continued to occur or fistula remained open, treatment was considered as failure. No antibiotics were advised for this condition. Each patient was informed to return for follow up after one year and then they were evaluated for discharge and closure of the fistula. Data thus obtained at the end of the study was subjected to statistical analysis. Statistical analysis was done using computer software SPSS version 23. Mean and standard deviation was calculated for continuous variables like age etc. and frequency and percentage was taken for categorical variables like, gender etc. Comparison of number of sessions for healing and non healing patients was done using a t test. $\mathrm{P}$ value of less than or equal to 0.05 was taken as significant.

\section{Results:}

A total of 57 patients presenting with anorectal fistula were included in the study. Mean and standard deviation of age was $38.7 \pm 3.34$ (Table I) while there were 51 males ( $89.5 \%$ ) and only 6 females (10.5) (Table II). A total of 19 patients received $60 \mathrm{ml}$ volume of ozone, 23 received $120 \mathrm{ml}$ volume of ozone and remaining 15 received $180 \mathrm{ml}$ volume of ozone (Table II). Means and standard deviation of sessions of treatment with ozone was $8.29 \pm 3.66$ (Table I). Closure of the fistula was seen in only 14 patients while 43 did not show any improvements or they had reoccurrence of anorectal fistula after getting treatment with ozone (Table II). Those patients who had closure of fistula were subjected to lesser number of ozone treatment sessions while failure of treatment was associated with greater number of ozone insufflation sessions.

Table I

Mean and Standard Deviation

\begin{tabular}{|c|c|c|}
\hline & Mean & Standard Deviation \\
\hline Age & 38.70 & 3.34 \\
\hline $\begin{array}{c}\text { Ozone Insufflation } \\
\text { Sessions }\end{array}$ & 8.29 & 3.66 \\
\hline
\end{tabular}


Table II

Frequency and Percentages

\begin{tabular}{|c|c|c|}
\hline Gender & Frequency & Percentage \\
\hline Male & 51 & 89.5 \\
\hline Female & 6 & 10.5 \\
\hline Total & 57 & 100.0 \\
\hline \multicolumn{3}{|c|}{ Volume of Ozone } \\
\hline 60 & 19 & 33.3 \\
\hline 120 & 23 & 40.4 \\
\hline 180 & 15 & 26.3 \\
\hline Total & 57 & 100.0 \\
\hline \multicolumn{3}{|c|}{ Fistula Tract Closure } \\
\hline Yes & 14 & 24.6 \\
\hline No & 43 & 75.4 \\
\hline Total & 57 & 100.0 \\
\hline
\end{tabular}

\section{Discussion:}

The results of our study show that after ozone insufflation, only 14 patients developed fistula closure. Fistula closure was determined on the basis of complete cessation of anorectal discharge through fistula and closure of fistula orifice. There were also few cases in which relapsing of the anorectal fistula occurred. There were no side effects of the treatment observed in any patient. Ozone treatment was safe and tolerable to all the patients. Safe and easy application and assessment of ozone insufflation are the advantages of this treatment modality. A number of chronic inflammatory conditions are treatable with the help of ozone insufflation including anorectal abscesses, Crohn's disease and ulcerative colitis ${ }^{11}$. Studies have also been performed for its use in enterocutaneous fistulas ${ }^{15}$. An experimental study was performed on rats to assess the efficacy of ozone treatment in acute necrotizing pancreatitis ${ }^{12}$. Healing of colonic anastomoses with use of intraperitoneal ozone insufflation has also been studied ${ }^{13}$. It has also been shown to improve the distal colitis in an experimental study 14. In current study, it was hypothesized that ozone insufflation might be useful in the treatment of anorectal fistula as it has shown to be efficient in treatment of other fistula through its healing effect and reduction of inflammation.

Thick mucus layer and other colonic content in the rectum can reduce the efficiency of ozone; therefore it is difficult to adjust the dose of rectal ozone insufflation. Moreover desired results and calibration of optimum amount of dose required to achieve these results is also difficult in cases of rectally administered ozone. In the previous study, a mean concentration of ozone was $30 \mu \mathrm{g} \backslash \mathrm{ml}$ for rectal insufflation. Rapid increase in concentration of ozone insufflation must be avoided and starting dose should be 3 to $5 \mu \mathrm{g} \backslash \mathrm{ml}$ and then gradually increased keeping in mind the tolerability by the patient. One side effect associated with rapid dose of ozone insufflation is severe abdominal cramps ${ }^{16}$. In this study starting dose was set as $10 \mu \mathrm{g} \backslash \mathrm{ml}$ and it was gradually increased up to $40 \mu \mathrm{g} \backslash \mathrm{ml}$. Almost similar adjustments were made for volume of ozone and volume was increased from 60 to 180 until ozone was felt by the patient reaching his her rectum. Insufflation of ozone can be done daily or on alternate days ${ }^{11}$. In this study dosing plan on alternate days was adapted to avoid the inconvenience of the patients.

Even though overall results of the treatment of anorectal fistula was unsatisfactory and ratio of treated fistula was very low but based on these results it can be recommended that ozone insufflation can be used as an alternative treatment in patients with uninfected, uncomplicated and short fistula tract. The possible reason behind prohibition of recovery can be presence of granulation tissue which is resistant to recovery and is found at the inner covering of the fistula. Ozone treatment even though cannot be first choice treatment in most patients but it can be used in elderly patients with concomitant co-morbidities, most effectively in patients with short fistula tract before attempting surgery. The results of our study are disappointing but its efficacy should be further evaluated with more research and with larger sample size. Debridement of granulation tissue before attempting the ozone insufflation might prove helpful in success of this treatment modality. Ozonide is known as ozone gas saturated by olive oil and water. Ozone gas present in ozonide has a longer half life therefore its healing effect in tissues can also last longer with use of ozonide. Therefore ozonide might also prove useful with its long lasting recovery enhancing effect on tissue ${ }^{11}$, when applied to the whole short and straighter tract of fistula. Before the 
start of ozone insufflation into the anorectal fistula, magnetic resonance imaging should be performed to enhance the overall success rate of ozone insufflation treatment.

\section{Conclusion:}

On the basis of the results of this study, it can be concluded that ozone insufflation is not a promising treatment option for the treatment of anorectal fistula. There were no associated side effects of ozone insufflation. Further studies are required with larger sample size.

\section{Conflict of interest:}

There was no conflict of interest regarding this study.

\section{Funding Source:}

No external funding source was used to complete this study.

\section{References:}

1- Nelson RL, Abcarian H. Epidemiology, incidence and prevalence of fistula in ano. InAnal Fistula 2014 (pp. 1-3). Springer New York

2- Prosst RL, Joos AK, Ehni W, Bussen D, Herold A. Prospective pilot study of anorectal fistula closure with the OTSC Proctology. Colorectal Dis. 2015;17(1):81-6.

3- Limura E, Giordano P. Modern management of anal fistula. World J Gastroenterol: WJG. 2015;21(1):12.

4- Qin SH, Cheng L, Selorm AL, Yuan FT. An Overview of Ozone Research. Journal Adv Oxid Technol. 2018;21(1):297-302.

5- Kist S, Kollmuss M, Jung J, Schubert S, Hickel R, Huth KC. Comparison of ozone gas and sodium hypochlorite/chlorhexidine two-visit disinfection protocols in treating apical periodontitis: a randomized controlled clinical trial. Clin oral invest. 2017;21(4):995-1005.

6- Hao K, Li Y, Feng J, Zhang W, Zhang Y, Ma N, Zeng Q, Pang H, Wang C, Xiao L, He X. Ozone promotes regeneration by regulating the inflammatory response in zebrafish. Int immunopharmacol. 2015;28(1):369-75.

7- Bocci VA. Scientific and medical aspects of ozone therapy. State of the art. Arch med res. 2006;37(4):425-35.

8- Corradi M, Alinovi R, Goldoni M, Vettori MV, Folesani G, Mozzoni P, Cavazzini S, Bergamaschi E, Rossi L, Mutti A. Biomarkers of oxidative stress after controlled human exposure to ozone. Toxicol lett. 2002;134(1-3):219-25.

9- Geng Y, Wang W, Ma Q, Peng LQ, Liang ZH. Ozone therapy combined with sulfasalazine delivered via a colon therapy system for treatment of ulcerative colitis. Nan fang yi ke da xue xue bao= J South Med Univ. 2010;30(12):2683-5.

10- Ozturk A, Atalay T, Cipe G, Luleci N. Ozone Treatment for Chronic Anal Fistula: It Is Not Promising. Indian J Surg. 2017;79(4):308-11.

11 - Sharma M, Hudson JB. Ozone gas is an effective and practical antibacterial agent. Am j infect control. 2008;36(8):559-63.

12- Uysal B, Yasar M, Ersoz N, Coskun O, Kilic A, Cayc T, Kurt B, Oter S, Korkmaz A, Guven A. Efficacy of hyperbaric oxygen therapy and medical ozone therapy in experimental acute necrotizing pancreatitis. Pancreas. 2010;39(1):9-15.

13- Erginel B, Erginel T, Aksoy B, Dokucu Aİ. Effect of ozone therapy (OT) on healing of colonic anastomosis in a rat model of peritonitis. Balk med j. 2014;31(3):249.

14- Altinel O, Demirbas S, Cakir E, Yaman H, Ozerhan IH, Duran E, Cayci T, Akgul EO, Ersoz N, Uysal B, Kurt B. Comparison of hyperbaric oxygen and medical ozone therapies in a rat model of experimental distal colitis. Scand j clin lab inv. 2011;71(3):185-92. 
15- Clavo B, Santana-Rodriguez N, Gutierrez D, Apodaca B, Lopez L, Febles G, Cruz F, Llontop P. Ozone therapy in the management of enterocutaneous fistulas resulting from postsurgery abdominal/pelvic mesh placement. Journal of pain and symptom management. 2012 Apr 1;43(4):e1-4.

16- Bocci V, Borrelli E, Travagli V, Zanardi I. The ozone paradox: ozone is a strong oxidant as well as a medical drug. Medicinal research reviews. 2009 Jul 1;29(4):646-82.. 